\title{
A Case Study on Custom Hiring of Combine Harvester in Pusa and Adjoining Area
}

\author{
Kundan Kumar, Vedprakash Kumar and Manoranjan Kumar*
}

\author{
College of Agricultural Engineering, Dr. Rajendra Prasad Central Agricultural University, \\ Pusa (Samastipur), Bihar-84812, India
}

*Corresponding author

\begin{abstract}
A B S T R A C T
Bihar state, after its division on November 15, 2000 has agriculture as a major instrument to combat a catastrophic situation as its economic and unemployment. The use of too expensive and high capacity farm machines through custom hiring suitable for agricultural harvesting operation and unhealthy socioeconomic conditions would help boost up its growth, economy and also solve the unemployment challenge. Hence a project undertaken a case study on custom hiring of combine harvester in Pusa and adjoining area with the objectives, To study the economic feasibility of use of combine harvester, evaluation of brake even point, major constraints for adoption of combine harvester. It was found only 2 to $3 \%$ farmer were above high secondary 76 to $77 \%$ were up to secondary and 18 to $20 \%$ of farmer were up to higher secondary. This was also a main factor for adoption of new technology for agricultural practice such as harvesting by combine harvester. The distribution of tool/implement shows in village Sakri less than $1 \%$ self-propelled reaper, less than $0.5 \%$ Tractor operated and about $1 \%$ of reaper-cum binder and combine harvester. This is the only cause of unawareness of harvesting implement and benefit. Due to less availability of electric power, farmers were not using electric motor operated thresher for threshing of paddy and wheat crop and also other agricultural practices. Farmer like more harvesting by wheat crop as compare to paddy by combine harvester because of residue use for animal feed. Combine harvester owner feel very much difficulty when breakdown of machine, due to lack of proper mechanic, service centre, spare etc. Cost of harvesting and threshing by combine was only Rs. 2386/ha for self-propelled combine harvester and Rs. 2248/ha for tractor operated combine harvester. The break-even point was obtained in 390 ha for self-propelled combine harvester and 246 ha for tractor operated combine harvester. Custom hiring business is more suitable of advance technology of agricultural practice, like harvesting of wheat and paddy crop combine harvester.
\end{abstract}

\section{Introduction}

Agriculture is the mainstay human activity and is of the strongholds of Indian economy accounting for 18.5 percent of the GDP. It represents the backbone of rural livelihood security system and is also a source of vital demand and supply to manufacturing sector. India has the second largest area of the arable land in the world. Wheat and Paddy are most staple crops in the country and they are grown over an area of about 40705 and 22307 lakhs ha respectively.

Bihar has slipped from fourth position in 1990-91 to sixth position in 2002-03 among the rice producing states of India. This is partly due to increase in production in other 
states and partly due to carving of new state of Jharkhand out of Bihar. Although Bihar has 8.9 per cent of the nee area of the country and about two-thirds of the cultivated area of the state is under nee cultivation, the state produces only 6.8 per cent of the total rice of India.

This is due to low average yield of only 13.9 quintals per hectare against 18 quintals for the country as a whole. About 25 districts of Bihar are producing rice but the main producing districts are Rohtas, Bhojpur, Purnea, Paschim Champaran, Purab Champaran, Aurangabad, Gaya, Bhagalpur, Patna and Gopalganj.

Bihar contributes $8.7 \%$ of the total area and $6.33 \%$ of the total production of wheat in the country. During the last 16 years (1980-81 to 1996-97) the area under wheat has risen from 17.55 lakh hectares to 22.3 lakh hectares and production from 23.06 lakh tones to 44.09 lakh tones ( $91.2 \%$ increase).

In recent years there has been some decline in the area and output of the wheat in the state (in 1997-98 area 20.81 lakh ha. and production 41.59 lakh tones; in 1998-99 production 44.03 lakh tones and in 2002-03 production 41.23 lakh tones). Here Middle Ganga Plain in the northern Bihar is important for wheat cultivation. Rohtas, Bhojpur, Munger, Saran, and Begusarai together contribute one-third to the state's output of wheat. Other districts worth of mention include Gopalganj, East Champaran, Purnea. Patna, and Muzaffarpur. The area under wheat decreases from west to east with the increasing humidity.

\section{Problems statement and objective the study}

There is growing trend of using combine harvesters in wheat and paddy cultivation in Bihar recently. After its division on
November 15, 2000 has agriculture as a major instrument to combat a catastrophic situation as its economic and unemployment. The use of too expensive and high capacity farm machines through custom hiring suitable for agricultural harvesting operation and unhealthy socio-economic conditions would help boost up its growth, economy and also solve the unemployment challenge. So the main objective of the study the economic feasibility of combine harvester usage in Bihar with reference to the economical, social aspect of farmers and major constraints in adoption in paddy and wheat cultivation.

\section{Materials and Methods}

Samastipur and Muzaffarpur district selected for survey on the basis of availability of combine harvester. 4 combine harvester owners were selected by using simple random sampling technique to collect primary data. Pre-tested questionnaire was employed to collect these field level data. Secondary data were extracted from related theoretical formula, Data analysis was done by using simple descriptive methods. The study was conducted with four combine harvester owners are following (Table 1)

$\mathrm{T}_{1}=$ Satish Kumar Dwivedi, Vill : Sakri, Block : Bandra, Dist : Muzaffarpur $\mathrm{T}_{2}=$ Prabhat Kumar Dwivedi Vill : Sakri, Block : Bandra, Dist : Muzaffarpur

$\mathrm{T}_{3}=$ Shudhansu Kumar Vill : Nayanagar, Block : Hasanpur, Dist : Samastipur $\mathrm{T}_{4}=$ Anand Kumar Rai Vill : Panchrukhi, Block : Jitwarpur, Dist : Samastipur.

\section{Field capacity}

The field capacity was calculated on the basis of area covered in the specific time for a particular operation. It was obtained by simply dividing the total area covered by the total time taken. 


\section{Harvesting operation data}

Harvesting is one of the main operations involved in crop production which consumes a large amount of human power traditionally. But know these days self-propelled and power operated (tractor) are widely used for cereal crop and other grown crop. Knowing total area covered by total number of human by sickle, self-propelled implement and power operated harvesting implement involved in the harvesting operation in specified time. Total human, self-propelled, tractors, power tiller operated hours were calculated.

\section{Threshing operation data}

In this operation power source have been considered to obtain the threshing hour and capacity of threshing (in terms output /input), the total grain production was calculated by multiplying the average yield of grain and area cropped under wheat, pulse and paddy etc. following expression was used to compute total time required for threshing.

\section{Hour of threshing= $\frac{\text { total wheat/paddy production (q) }}{\text { Output of threshere }\left(\frac{\mathrm{q}}{\mathrm{h}}\right)}$}

Hours of threshing where estimated by considering all threshing operation to be completed by tractor, electric motor and diesel engine etc.

\section{Custom hiring data}

Combine harvester, Reaper, Reaper cum binder use for harvesting as custom hiring purpose. They did not of hours spent for custom hiring but at the same time they were very well enable to remember total amount of money received from custom hiring. Thus custom hour was obtained by following expression.
Custom hours $=$

Total amount of money received (Rs)

$$
\text { custom rate }\left(\frac{\mathrm{RS}}{\mathrm{h}}\right)
$$

\section{Calculation for cost of use of combine harvester and custom hiring rate}

To assist those farmers wanting to contract out machinery by showing them how to properly calculate their costs, this will help them arrive at a fair and realistic fee. Commonly, farmers wanting extra income will contract out their machinery but they tend to undercharge.

\section{Fixed cost}

Fixed costs are costs which don't vary with usage. You pay these costs every year regardless of whether you use your machine for 10 years or 1,000 hours. Fixed cost are Insurance, Depreciation, Interest cost, Shedding cost.

\section{Variable costs (operating costs)}

Variable costs are those costs which vary in proportion to the machine's use. They are sometimes called operating costs, because they occur only when the machine is operated. The main variables costs are Fuel, oil and grease, and wearing parts Repairs and maintenance, Timeliness costs

\section{Working out a contract rate}

\section{Allowing for contingencies}

Contingencies are incidental expenses. When estimating machinery costs to calculate a contract rate, you should allow for a least the following contingencies:

Travelling and machinery transportation costs not already included in your fixed or variable costs 
Accommodation if working away from home Weather (for example, no work due to flood or drought). Weather is very important if you have permanent workers who are paid regardless of work availability

Phone, power and office rent

Fuel - sometimes the farmers prefer the contractors cannot claim the diesel rebate. Fortunately, it is more common for the farmers to provide the fuel as they can claim the diesel rebate.

These incidental expenses occur depending on how you run your business and what your work entails. You can add on some of these costs as they occur (such as overnight accommodation on jobs away from home, or transportation costs) and you can build the others into your contract rate (such as business phone, power costs, and work risk).

\section{Allowing for a profit margin}

Unless you are doing someone a favors, a profit margin needs to be built into your contract rate to make doing the work worthwhile. This can be done by adding a flat rate per hour on top of the contract rate, or by adding on a percentage of the machinery costs to the contract rate. Alternatively, if you are an owner-operator, you can accept the labour cost as your profit margin. If you are doing the work for someone as a favor, it is important to ensure that at least all variable (operating) costs are covered when undertaking the work, otherwise you are effectively paying to do that work.

\section{Break-even analysis}

Break-even analysis is a useful study the relationship between fixed costs, variable costs and returns. A break-even point defines an investment will generate a positive return and can be determined graphically or with simple mathematics. Brea-even analysis computes the volume of production at a given price necessary to cover all costs (Fig. 1).

\section{Mathematical explanation}

The graphic method of analysis helps the concept of the break-even point. However, graphing the cost and income lines is laborious. The break-even point is found faster and more accurately with the following formula:

$\mathrm{B}-\mathrm{E}=\mathrm{F} /(\mathrm{S}-\mathrm{V})$

Where, B-E = Break-even point (units of production),

$\mathrm{F}=$ total fixed costs,

$\mathrm{V}=$ variable costs per unit of production,

$\mathrm{S}=$ savings or additional returns per unit of production.

\section{Constraints}

The farmers with small holdings especially in rain fed areas can hardly afford modernization of agriculture without financial support and incentive as farmers as not able to generate adequate returns to invest in agriculture for purchase of machinery. The area under hill agriculture Diara, Tal shifting cultivation is otherwise not suitable for use of mechanical power. The farmers in their regions will depend upon human and drought animal till a suitable light weight power source is developed. Farm machines in India are also available for limited operations, Machines yet to be developed to a level of perfection acceptable to be the farmers. Paddy which is grown in more than 44 million hectare needs better attention of the designers. Use of combine harvester and burning of straw is creating environmental pollution and farmers are losing valuable animal feed material, like wise environment, safety and health aspects in design and operation of farm nations need better attention. Use of agricultural machines 
in India by the farmers has been selective due to agro-ecological and socio-economical diversities. Improved machines have been adopted but present trend is for high capacity machines to be used a custom hiring and for contractual field operations.

\section{Results and Discussion}

Intensive cultivation in Bihar had been realized through the mechanization of the farms. The number of all types of farm machinery in the state available exponentially over time and as a result Bihar became the less mechanized state in India. However, over capitalization of the agriculture in Bihar, particularly on the machinery front is being seen as the prime cause of escalation of costs resulting in falling agricultural profitability. The provision of custom hiring of farm machinery services through private owner of bigger machine established is very important for the sustainability of their services in the long run. Keeping in view the objectives the results of present study are presented and discussed in the following sections:

Information regarding use of combine harvester in the four samples taken from the Pusa and its adjoining area. It was found that $\mathrm{T}_{1}$ was covered Samastipur, muzaffarpur and Darbhanga district, and $T_{2}$ his own brother covers the same district, and also $\mathrm{T}_{4}$ covered these three districts. But $\mathrm{T}_{4}$ after purchase of two year he was used in custom hiring near his native place Nayanagar, Hasanpur as custom hiring basis. After two year he was using own farm only in paddy as well as wheat crop.

It was observed that out of three districts of total paddy and wheat grown area about 389186 ha and 289527 ha respectively in which $0.067 \%$ and $0.125 \%$ were covered by $\mathrm{T}_{1} \mathrm{~T}_{2} \mathrm{~T}_{4}$ respectively. Whereas $\mathrm{T}_{3}$ as discuss earlier table he was covered only $0.048 \%$ of paddy and $0.058 \%$ of wheat in the Samastipur district of total grown area of paddy and wheat are 145262 ha and 137470 ha respectively.

It was observed more than $76 \%$ up to $80.42 \%$ farmer belong to marginal and small category, 13 to $14 \%$ farmer belong to semi medium, 4 to $5 \%$ farmer belong to medium and only about 1.42 to $2.17 \%$ farmer belong to large category in projected village respectively.

During survey study on education level among the farmer where also conducted in the $\mathrm{T}_{1}, \mathrm{~T} 3$ and $\mathrm{T}_{4}$. It was found only 2 to $3 \%$ farmer were above high secondary level 76 to $77 \%$ were up to secondary level and 18 to $20 \%$ of farmer were up to higher secondary level. This was also a main factor for adoption of new technology for agricultural practice such as harvesting by combine harvest (Table 2 and 3 ).

Figure 2 bar chat shows that how repair and maintenance cost is needed for an owner of combine harvester after purchase in both type self-propelled as well as tractor operated. Initially the cost is less due to not require of servicing. After using of one year need comparatively higher and constant. After three year of using there was need of more repair cost. It was because of their neither service center nor any special mechanic or any expert operators were available in this north Bihar region. It was critically observed that non-availability of service centre mechanic and expert operator of combine harvester. Shows the annual profit of combine harvester owner it was found year by year the profit margin was increasing for $\mathrm{T}_{1} \mathrm{~T}_{2} \mathrm{~T}_{4}$ but in case of $T_{3}$ constant because of not more using as custom hiring. He said his combine harvester was harvesting own farm and some of local farm. So, graph clearly shows that custom hiring of combine harvester was profitable business for owner. Table 4 shows the farmer response about harvesting practice conducted by combine harvester. it was found 
$52 \%$ in $\mathrm{T}_{1} 59 \%$ in $\mathrm{T}_{3}$ and $51 \% \mathrm{~T}_{4}$ farmer were using by self-willing, Whereas $31 \%$, $23 \%$ and $34 \%$ respectively using by owner motivation and only $16 \%, 17 \%$ and $14 \%$ farmer were seeing in believe.

The table 5 shows the farmers opinion for harvesting of crop by different method. It was observed that $68.96 \%$ in $\mathrm{T}_{1}, 71.43 \%$ in $\mathrm{T}_{3}$ and $76.09 \%$ in $\mathrm{T}_{4}$ farmers used sickle whereas $5.53 \%$ in $\mathrm{T}_{1}$ and $8.57 \%$ in $\mathrm{T}_{3}$ farmers used Reaper, $8.96 \%$ in $\mathrm{T}_{1}, 11.91 \%$ in $\mathrm{T}_{3}, 8.69 \%$ in $\mathrm{T}_{4}$ farmers used Reaper cum binder and $16.55 \%$ in $\mathrm{T}_{1}, 8.09 \%$ in $\mathrm{T}_{3}, 15.22 \%$ in $\mathrm{T}_{4}$ farmers used combine harvester for harvesting of crop respectively. It was recorded the mostly farmer till date using sickle for harvesting and secondly combine harvester. It was due to harvesting, threshing and storing operation simultaneously take lesser time.

The cost of combining was less than cost of harvesting and threshing by all the other methods. The cost of combining by selfpropelled and tractor operated combine harvester was calculated as Rs. 1909/ha and Rs. 1775/ha whereas, by reaper cum binder thresher system, self-propelled reaper thresher system, tractor operated reaper thresher system and manually system were Rs. 4062/ha, 4138/ha, 4948/ha and 8734/ha respectively. All cost calculation is given in annexure 4 to annexure 10 .

During the survey it was also recorded the custom hiring charge taken by the owner of the entire four combine harvester in terms of Rs/ha also asked by the user. It was found that the average rate charges by the owner was 3000/ha, user said that the owner of combine harvester also bargaining for hiring charge and it was charges 3000 to 3100/ha. But cost of combine harvester charge by straight line method was calculated. It was found 2386/ha for self-propelled combine harvester and 2248/ha for tractor operated combine harvester. There was found approx. Rs 700/ha difference between the actual and calculated. This difference is due to monopoly during pick season of harvesting.

It was also asked during survey by the owner of self-propelled Reaper and self-propelled reaper cum binder and found no any owner said about their machine used in custom hiring. The tractor operated Reaper cum binder owner said Rs. 800/acre (2000/ha) hiring charge was taken. It was only for harvesting of paddy and wheat crop and leave them in swath. In view of economy it was found combine harvester was most suitable for paddy and wheat crop because harvesting and other operation after harvesting was conducted simultaneously.

From the table 4, the break-even point was evaluated under local condition and found 390 ha for self-propelled combine harvester and 246 ha for tractor operated combine harvester. But theoretically calculated breakeven point was found 468 ha for selfpropelled combine harvester and 271 ha for tractor operated combine harvester. All cost calculation is given in annexure 11 and annexure 12 (Fig. 3 and 4 and table 7).

\section{Constraints}

The main constraint for non-adoption was higher cost.

Lack of road facility to reach the agriculture field.

Maximum land was in small, marginal and non-consolidation land.

Only progressive farmer were in the main adopters of new production technologies including combine harvester for harvesting of paddy and wheat crop.

Awareness about combine harvester and convincing the aged farmer is also a factor of poor adoption.

Collection of straw after harvesting of paddy and wheat crop is a major constraint was found. 
Table.1 Combine harvester owner of projected area

\begin{tabular}{|c|c|c|c|l|}
\hline $\begin{array}{c}\text { S. } \\
\text { No. }\end{array}$ & Treatment & $\begin{array}{c}\text { Year of } \\
\text { purchase }\end{array}$ & $\begin{array}{c}\text { Purchase } \\
\text { price (lakh) }\end{array}$ & \multicolumn{1}{|c|}{ Covered district of Bihar } \\
\hline & $\mathrm{T}_{1}$ & 2009 & 13.0 & Samastipur, Muzaffarpur, Darbhanga \\
\hline & $\mathrm{T}_{2}$ & 2013 & 12.0 & Samastipur \\
\hline & $\mathrm{T}_{3}$ & 2010 & 15.0 & Samastipur, Muzaffarpur, Darbhanga \\
\hline & $\mathrm{T}_{4}$ & 2009 & 14.0 & Samastipur, Muzaffarpur, Darbhanga \\
\hline
\end{tabular}

Table.2 Distribution of total paddy and wheat grown projected and coverage area

\begin{tabular}{|c|c|c|c|c|}
\hline S. No. & Treatments & Total projected area (ha) & Crop & Total coverage area, $\%$ \\
\hline \multirow{2}{*}{$\mathbf{1 .}$} & $\mathrm{T}_{1}$ & 389186 & Paddy & $\mathbf{0 . 0 2 3}$ \\
\hline \multirow{2}{*}{$\mathbf{2 .}$} & & 289527 & Wheat & $\mathbf{0 . 0 4 1}$ \\
\hline \multirow{2}{*}{$\mathbf{3 .}$} & $\mathrm{T}_{2}$ & 389186 & Paddy & $\mathbf{0 . 0 2 6}$ \\
\cline { 3 - 5 } & & 289527 & Wheat & $\mathbf{0 . 0 4 9}$ \\
\hline \multirow{2}{*}{$\mathbf{4 .}$} & $\mathrm{T}_{3}$ & 145262 & Paddy & $\mathbf{0 . 0 4 8}$ \\
\hline & $\mathrm{T}_{4}$ & 137470 & Wheat & $\mathbf{0 . 0 5 8}$ \\
\hline & & 389186 & Paddy & $\mathbf{0 . 0 1 8}$ \\
\hline
\end{tabular}

Table.3 Land holding pattern of projected village

\begin{tabular}{|c|c|c|c|c|c|c|}
\hline $\begin{array}{l}\text { S. } \\
\text { No. }\end{array}$ & $\begin{array}{c}\text { Treatmen } \\
\mathbf{t}\end{array}$ & $\begin{array}{c}\text { Marginal } \\
\text { ( }<\text { I ha }), \%\end{array}$ & $\begin{array}{c}\text { Small } \\
\text { (1-2 ha) } \\
\%\end{array}$ & $\begin{array}{l}\text { Semi medium } \\
\text { ( } 2-4 \text { ha), } \%\end{array}$ & $\begin{array}{c}\text { Medium } \\
\text { (4-10 ha) } \%\end{array}$ & $\begin{array}{c}\text { Large } \\
(>10 \text { ha }) \\
\%\end{array}$ \\
\hline 1 & $\mathrm{~T}_{1}$ & 44.82 & 34.48 & 13.79 & 5.17 & 1.72 \\
\hline 2 & $\mathrm{~T}_{3}$ & 40.47 & 35.71 & 13.66 & 5.71 & 1.42 \\
\hline 3 & $\mathrm{~T}_{4}$ & 43.47 & 36.95 & 13.04 & 4.34 & 2.17 \\
\hline
\end{tabular}

Table.4 Farmer response

\begin{tabular}{|c|c|c|c|c|}
\hline S. No. & Village & Self-willing (\%) & Motivated by owner (\%) & Seen other farmer (\%) \\
\hline $\mathbf{1}$ & $\mathrm{T}_{1}$ & 52.09 & 31.25 & 16.6 \\
\hline $\mathbf{2}$ & $\mathrm{T}_{3}$ & 58.82 & 23.53 & 17.65 \\
\hline $\mathbf{3}$ & $\mathrm{T}_{4}$ & 51.43 & 34.29 & 14.28 \\
\hline
\end{tabular}


Table.5 General Opinion of farmer for harvesting of crop

\begin{tabular}{|c|c|c|c|c|c|}
\hline $\begin{array}{c}\text { S. } \\
\text { No. }\end{array}$ & Village & $\begin{array}{c}\text { Sickle } \\
(\mathbf{\%})\end{array}$ & $\begin{array}{c}\text { Reaper } \\
\mathbf{( \% )}\end{array}$ & $\begin{array}{c}\text { Reaper cum binder } \\
\mathbf{( \% )}\end{array}$ & $\begin{array}{c}\text { Combine harvester } \\
\mathbf{( \% )}\end{array}$ \\
\hline $\mathbf{1}$ & $\mathrm{T}_{1}$ & 68.96 & 5.53 & 8.96 & 16.55 \\
\hline $\mathbf{2}$ & $\mathrm{T}_{3}$ & 71.43 & 8.57 & 11.91 & 8.09 \\
\hline $\mathbf{3}$ & $\mathrm{T}_{4}$ & 76.09 & 0 & 8.69 & 15.22 \\
\hline
\end{tabular}

Table.6 Cost of use of different implement and manual method

\begin{tabular}{|r|l|c|}
\hline S.N. & \multicolumn{1}{|c|}{ Different method } & Cost of use (Rs./ha) \\
\hline $\mathbf{1}$ & Self-propelled combine harvester & 1909 \\
\hline $\mathbf{2}$ & Tractor operated combine harvester & 1775 \\
\hline $\mathbf{3}$ & Reaper cum binder + Thresher & 4062 \\
\hline $\mathbf{4}$ & Self-propelled reaper + thresher & 4138 \\
\hline $\mathbf{5}$ & Tractor operated reaper + thresher & 4948 \\
\hline $\mathbf{6}$ & Manually & 8734 \\
\hline
\end{tabular}

Table.7 Evaluation of break-even point

\begin{tabular}{|c|l|c|c|}
\hline $\begin{array}{c}\text { S. } \\
\text { No. }\end{array}$ & \multicolumn{1}{|c|}{ Type of combine harvester } & $\begin{array}{c}\text { Calculated B.E.P. } \\
\text { (ha) }\end{array}$ & Actual B.E.P. (ha). \\
\hline $\mathbf{1}$ & Self-propelled combine harvester & 468 & 390 \\
\hline $\mathbf{2}$ & Tractor operated combine harvester & 271 & 246 \\
\hline
\end{tabular}

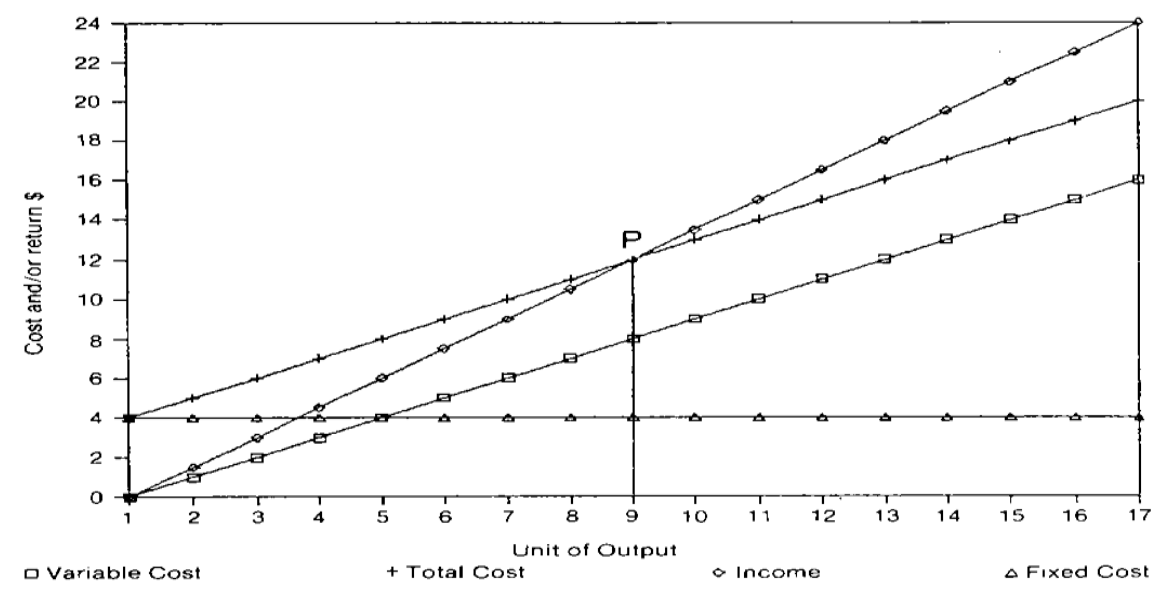

Fig.1 Break-even analysis 


\section{Education level \%}

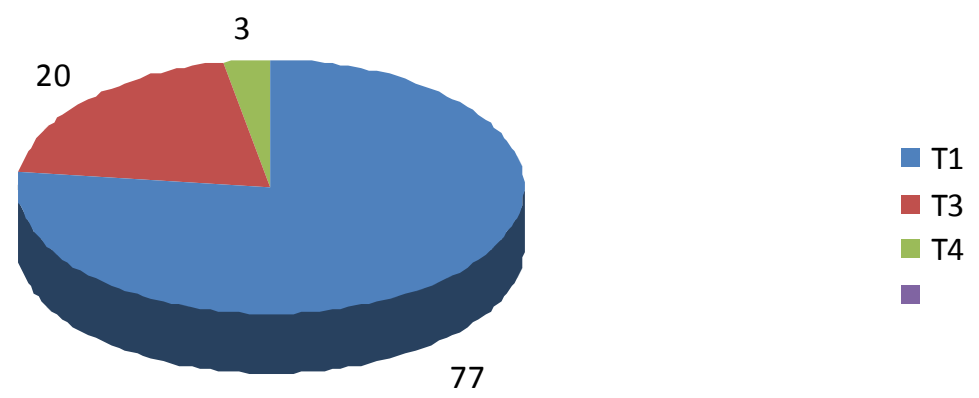

Fig.2

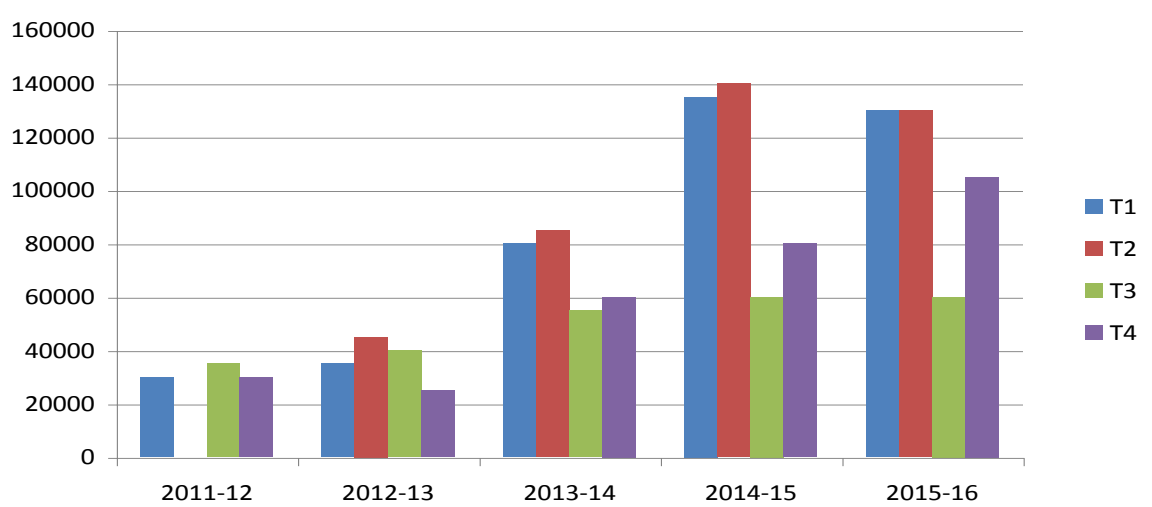

Fig.3 Repair and maintenance cost of owner

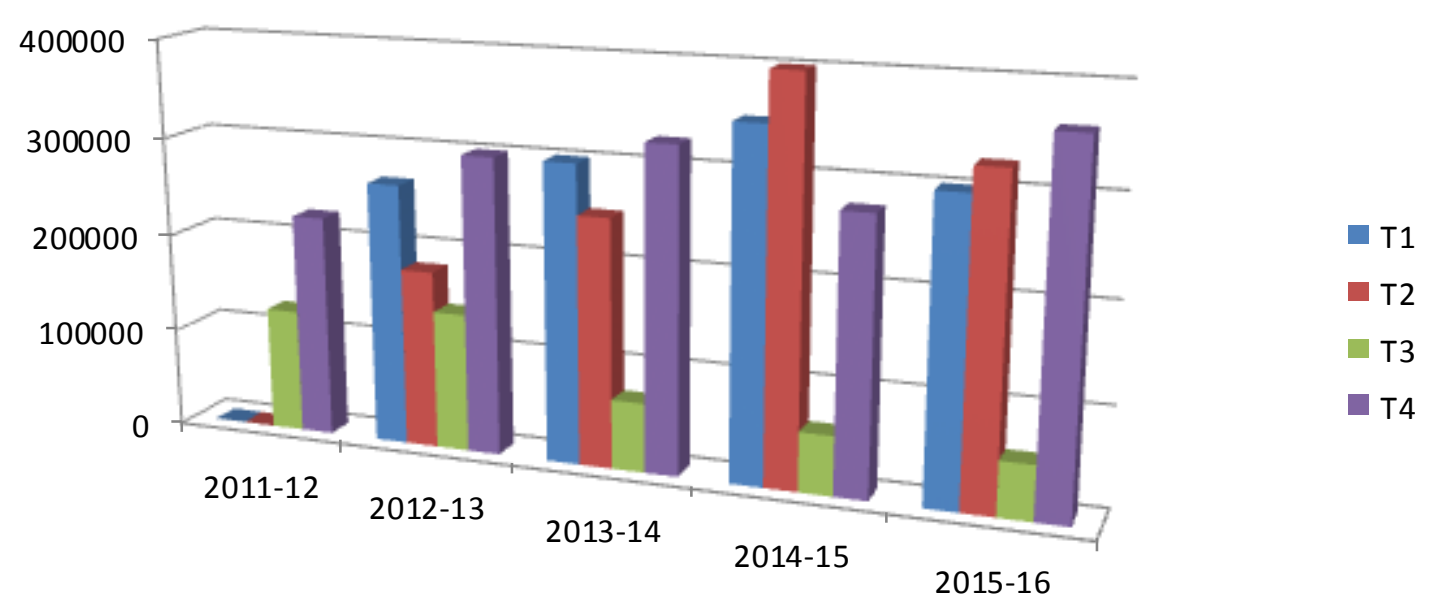

Fig.4 Annual profit of owner

In surveyed village, more than $76 \%$ up to $80.42 \%$ farmer belong to marginal and small category, 13 to $14 \%$ farmer belong to semi medium, 4 to $5 \%$ farmer belong to medium and only about 1.42 to $2.17 \%$ farmer belong to large category in projected village respectively. Fragmented land and transportation difficulty (small width road and electric wire) was the 
major constraint in the adoption for combine harvester.

It was found only 2 to $3 \%$ farmer were above high secondary 76 to $77 \%$ were up to secondary and 18 to $20 \%$ of farmer were up to higher secondary. This was also a main factor for adoption of new technology for agricultural practice such as harvesting by combine harvester. The distribution of tool/implement shows in $\mathrm{T}_{1}$ less than $1 \%$ self-propelled reaper, less than $0.5 \%$ Tractor operated and about $1 \%$ of reaper-cum binder and combine harvester.

This is the only cause of unawareness of harvesting implement and benefit. Due to less availability of electric power, farmers were not using electric motor operated thresher for threshing of paddy and wheat crop and also other agricultural practices. Farmer like more harvesting by wheat crop as compare to paddy by combine harvester because of residue use for animal feed. Combine harvester owner feel very much difficulty when breakdown of machine, due to lack of proper mechanic, service centre, spare etc.

Cost of harvesting and threshing by combine was only Rs. 2386/ha for self-propelled combine harvester and Rs. 2248/ha for tractor operated combine harvester. The break-even point was obtained in 390 ha for self-propelled combine harvester and 246 ha for tractor operated combine harvester. Custom hiring business is more suitable of advance technology of agricultural practice, like harvesting of wheat and paddy crop combine harvester (Table 6).

\section{References}

Aggarwal, S. and Yadav, S. (2000). Economic analysis of utilization of farm tractors districts of Haryana. Agri. Engg. Today, 24(1): 14-21.

Beaton, A.J.; Dhuyvetter, K.C. and Kastens, T.L. (2003). Custom rates and the total cost to own and operate farm machinery in Kansas.

Bhatia, B.S. (2000). Tractor $-\mathrm{a}$ boon or bane for Punjab farmers. The Tribune, Chandigarh Edition, Chandigarh, October 16, 2011.

Kaur, K. (1988). Economics of custom hiring of agricultural machinery in the Punjab state. M.sc. Thesis (Unpublished), Punjab Agricultural University, Ludhiana, India.

Nagarajan, S.S. (2004). Role of farm implements in crop production. Agro India, 8 (5): 12-14.

Satapathy, K. (2004). Farm mechanization. Agro India, 8 (6): 30-32.

Sharma, J.L. (1974). An analytical study into custom hiring services vis-à-vis agricultural resource productivity. M.sc. Thesis (Unpublished), Punjab Agricultural University, Ludhiana, India.

Tabshnikov, A. T., (1983): Improving the productivity of a combine harvester. Mekhanizatsiya I Elektrifikatsita Sel' skogo Khozyaistva (9): 5-6.

Tiwari, D., Kumar, R., Singh, G. and Yadav, S.P. (2005). Entrepreneurship development through promotion of custom hiring of paddy transplanter: Case study. International Journal of Enhanced Research in Science, Technology \& Engineering. 4(6): 451-456.

\section{How to cite this article:}

Kundan Kumar, Vedprakash Kumar, Manoranjan Kumar. 2020. A Case Study on Custom Hiring of Combine Harvester in Pusa and Adjoining Area. Int.J.Curr.Microbiol.App.Sci. 9(04): 2504-2513. doi: https://doi.org/10.20546/ijcmas.2020.904.300 